\title{
Process Temperature Profile and Rheological Properties of Greases from Vegetable Oils
}

\author{
Leticia M. Lazaro ${ }^{1}$, Donato A. G. Aranda ${ }^{2}$ \\ ${ }^{1}$ Petrobras Research Center, Rio de Janeiro, Brazil \\ ${ }^{2}$ Federal University of Rio de Janeiro (UFRJ), Rio de Janeiro, Brazil \\ Email: lmlazaro@petrobras.com.br
}

Received December 18, 2013; revised January 18, 2014; accepted January 25, 2014

Copyright (C) 2014 Leticia M. Lazaro, Donato A. G. Aranda. This is an open access article distributed under the Creative Commons Attribution License, which permits unrestricted use, distribution, and reproduction in any medium, provided the original work is properly cited. In accordance of the Creative Commons Attribution License all Copyrights (C) 2014 are reserved for SCIRP and the owner of the intellectual property Leticia M. Lazaro, Donato A. G. Aranda. All Copyright (C) 2014 are guarded by law and by SCIRP as a guardian.

\begin{abstract}
Greases are composed by lubricating oil dispersed in a thickener that can be a metal soap, polymers or clays. Grease production using vegetable oils is increasing due to biodegradability requirements. Since vegetable oils present a worse oxidation and hydrolysis stability than mineral oils, it is usually difficult to produce a neutral grease using them. Four greases were produced using soybean oil as lubricating oil and lithium 12-hydroxystearate as thickener. The maximum temperature of reaction was ranged from $230^{\circ} \mathrm{C}$ to $120^{\circ} \mathrm{C}$ in a bench process and a reduction in the final product acidity was observed (from $8.2 \%$ acid to $0.05 \%$ alkaline). Traditional tests to evaluate thickener structure resistance like 10,000-time worked penetration, roll stability and dropping point were performed and results compared. In addition, rheological tests were performed and the results were also compared. Results indicate that it is possible to produce a quite neutral grease using vegetable oils with good thickener structure properties.
\end{abstract}

\section{KEYWORDS}

Grease; Vegetable Oil; Acid; Rheology

\section{Introduction}

The use of raw materials from renewable sources like vegetable oils helps increasing process sustainability.

Vegetable oils as lubricants have some issues like oxidation and hydrolysis stability and low temperature properties. On the other hand they present a quick biodegradability, very desirable in applications where leaks and environmental contamination are difficult to be avoided like outboard 2-stroke engines, railway track greases and wire ropes [1].

Grease production demands high temperature and it is difficult to avoid vegetable oils hydrolysis and acid generation under this condition. So, usually, greases with vegetable oils present some acidity.

Biodegradable lubricants have been adopted in many applications mainly due to regulation exigencies. For instance, the US Environmental Protection Agency is proposing rules to reduce the environmental impact of vessels and boats circulation by obliging them to use biodegradable, non-toxic and not bioaccumulative lubricants in oil-to-sea interfaces. This regulation will be valid after December 2013 (Vessel General Permit-VGP) [2].

Biodegradable grease must be produced using biodegradable components: thickener, base oil and additives. Lithium soap greases made with vegetable oils (soybean and castor oil) can be considered biodegradable by CECL-33-A-94 test method [3].

Lithium soap greases (Lithium 12-hydroxystearate as thickener) were produced using soybean oil as main lubricant component. Different maximum temperatures were used during production process and their influence in greases properties was evaluated. Besides regular grease properties, like worked cone penetration, dropping point and roll stability, rheological ones were also measured to evaluate thickener structure properties. 


\section{Methods}

The usual grease properties evaluated in the produced grease samples were based on ASTM Standard Methods [4].

- Consistency-60 time worked and 10,000 time worked penetrations (ASTM D 271),

- Dropping point (ASTM D 566),

- Roll stability (ASTM D 1831),

- Acidity or Alkalinity (ASTM D 128).

The worked cone penetration is measured after submitting grease sample to a grease worker, which consists of a device that forces the grease sample through a perforated plate many times. The difference between the 10,000 -time worked penetration and the 60-time one is used to evaluate the thickener structure stability.

The roll stability test consists of submitting grease sample to a low shear in the test apparatus. The consistency is measured before and after the shear procedure and the difference between these values is also related to thickener structure resistance.

When a grease sample is submitted to increasing temperatures, it gets softer until it becomes liquid. The dropping point is an evaluation of the highest temperature a grease can be submitted to until its structure is destroyed by heat.

Acidity and alkalinity are measured to evaluate how efficient the saponification step was. A neutral or slightly alkaline grease is desirable.

\section{Rheological Properties}

Greases are non-Newtonian fluids. They behave mostly like a pseudoplastic fluid with a yield stress.

Under low stresses, in the linear visco-elastic range (LVE), greases behave like a solid. They deform under stress but recover the initial structure when the stress is no longer applied.

As long as stress increases, their structure modifies until a point from which they do not behave just like a solid anymore. At this point, the end of linear viscoelastic range (LVE), the storage modulus (G') starts to decline until the cross over point, when it equals the viscous modulus (G”). The storage modulus refers to material solid behavior while the viscous modulus refers to liquid behavior. So when storage modulus G' is larger than viscous modulus G”, the sample behaves more like a solid. These properties are related to grease performance during lubrication and add information about thickener structure.

The rheological properties chosen allow to define three different regions in a grease rheological analysis:

- Below the LVE stress—sample behaves like a solid— linear viscoelasticity;

- Between LVE stress and cross over point where the yield stress is measured—sample presents both solid and liquid behavior;

- Over yield stress-sample flows and behaves like a liquid.

These curves can be both obtained by a stress sweep or a strain sweep test. In this study the strain sweep was chosen after a previous time sweep at low stress to stabilize the grease sample.

The rheological properties (storage modulus (G'), LVE stress and yield stress) were measured in a dynamic shear rheometer (oscillatory tests) AR-G2 from TA Instruments with the conditions presented on Table 1.

The storage modulus G' was calculated through the mean of last values measured during the time sweep step. The average was considered acceptable when the standard deviation was below $0.5 \%$ of the average value.

The LVE stress is the maximum stress at which the sample still is in a linear viscoelasticity region (storage modulus plateau) in a strain sweep analysis. It was measured at the highest \%strain where equipment torque still showed proportional and linear correlation with \% strain. The straight line was considered when presenting an $\mathrm{R}^{2}$ minimum of 0.99990 .

The yield stress was calculated at the cross over point where the storage modulus (G') equals the viscous modulus (G”) and the phase angle ( $\delta$ ) equals $45^{\circ}$. The phase angle measures the difference between stress applied and sample response through deformation (\%strain).

These calculations are illustrated in Figures 1 and 2.

\section{Greases Production}

The greases were produced in a cylindrical stainless steel reactor with stirring system adapted for grease production. The temperature needed was obtained through electric resistances and a temperature control system.

The raw materials used were 12-hydroxystearic acid, lithium hydroxide and soybean oil.

The initial steps for each reaction were the same:

- Feeding the reactor with part of soybean oil, total amount of 12-hydroxystearic acid and lithium hydroxide and

Table 1. Rheometer conditions.

\begin{tabular}{cc}
\hline Geometry & $\begin{array}{c}\text { Parallel plates with sand paper applied } \\
\text { over top plate to avoid slipping effects }\end{array}$ \\
\hline Diameter & $25 \mathrm{~mm}$ \\
Temperature & $25^{\circ} \mathrm{C}$ \\
Test & $\begin{array}{c}\text { Time sweep of } 30 \text { minutes at low \%strain } \\
\text { followed by oscillatory strain sweep }\end{array}$ \\
Range & 0.01 to $1000 \%$ strain \\
Frequency & $1 \mathrm{~Hz}$ \\
Equilibrium time & $1 \mathrm{minute}$ \\
Gap & $1 \mathrm{~mm}$ \\
\hline
\end{tabular}




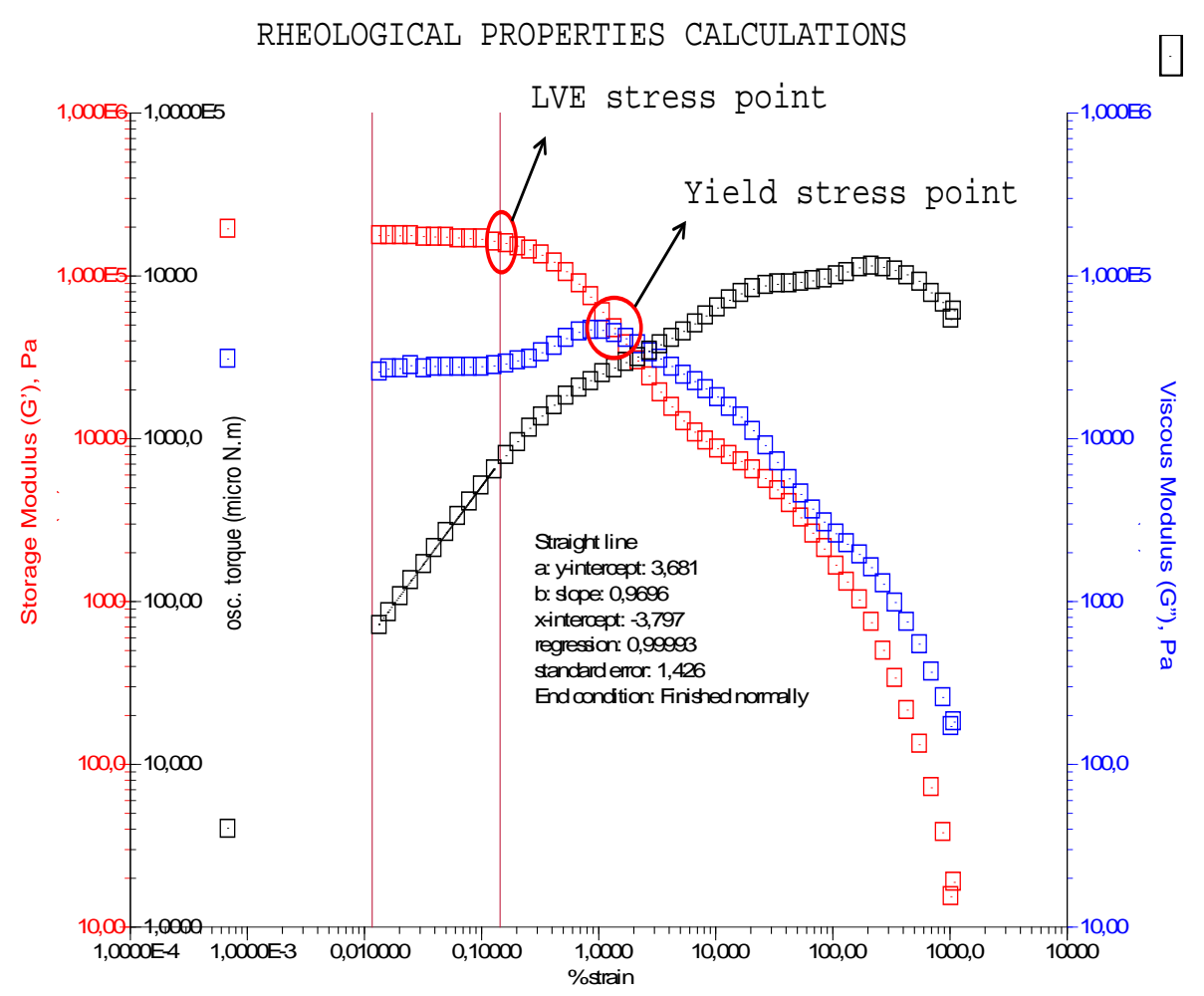

Figure 1. LVE and yield stress calculations.

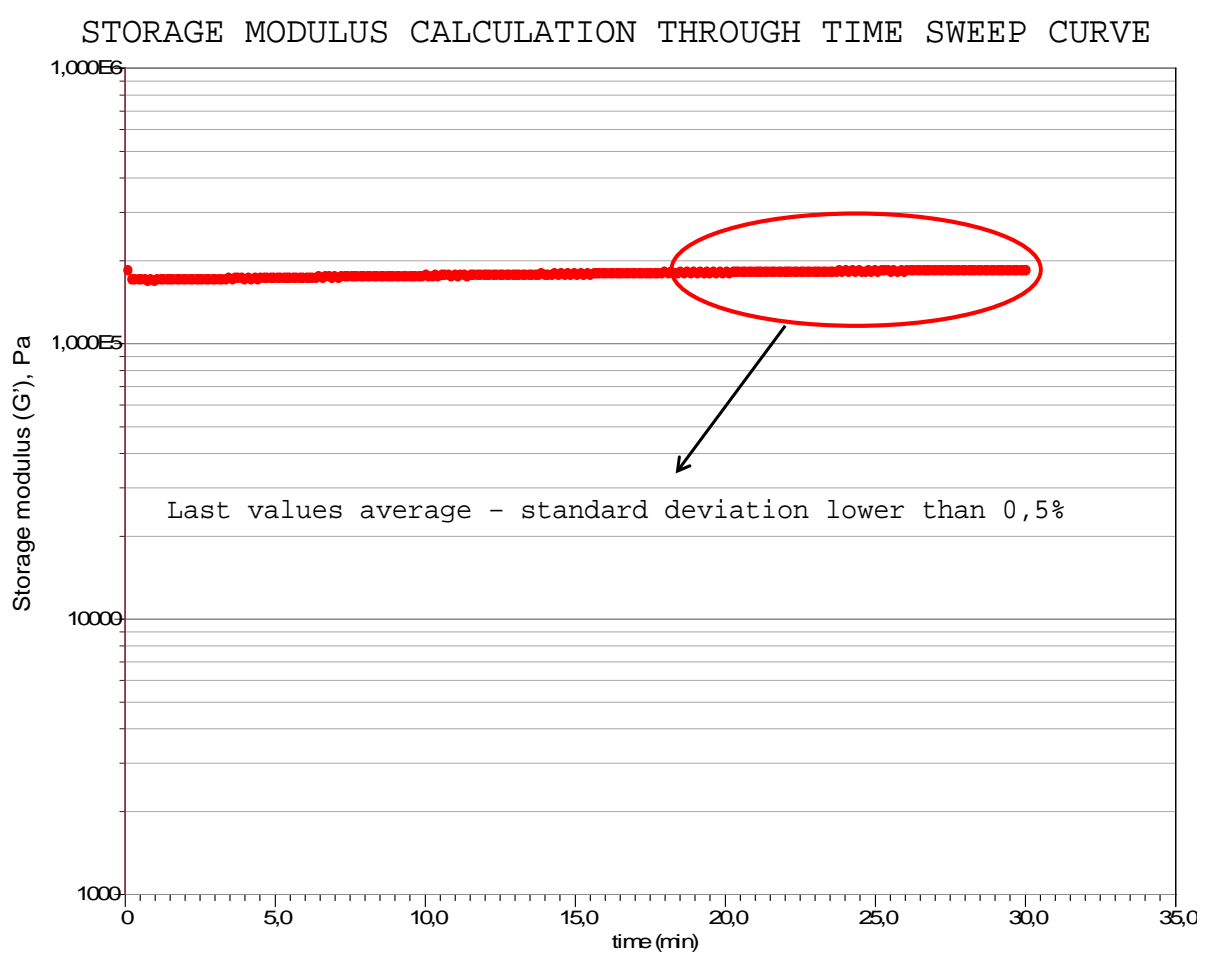

Figure 2. Storage modulus (G') calculation.

- Heating this mixture up to $115^{\circ} \mathrm{C}$ to $120^{\circ} \mathrm{C}$ with vacuum keeping at this temperature level for 2 hours to promote saponification and water removal.
The following steps for each batch are presented in Table 2.

The main difference among the batches was the 
Table 2. Batches process additional steps.

\begin{tabular}{cc}
\hline Batch & Final process steps \\
\hline SOY1 & Heating the mixture up to $230^{\circ} \mathrm{C}$, quench with $90 \mathrm{~g}$ of soybean oil and quick cooling followed by final oil addition and slow cooling \\
SOY2 & Heating the mixture up to $180^{\circ} \mathrm{C}$ and keeping it at this temperature for 1 hour followed by final oil addition and slow cooling \\
SOY3 & Heating the mixture up to $150^{\circ} \mathrm{C}$ and keeping it at this temperature for 1 hour followed by final oil addition and slow cooling \\
SOY4 & Heating the mixture up to $120^{\circ} \mathrm{C}$ and keeping it at this temperature for 1 hour followed by final oil addition and slow cooling \\
\hline
\end{tabular}

maximum process temperature after saponification step.

All batches were milled in a roller mill using the same adjustments.

\section{Results and Discussion}

The test results for all grease samples are presented in Table 3.

The maximum temperature is related to soap crystallization process. In SOY1 process, the initial crystal was induced by quench, which is a quick reduction in temperature obtained through addition of oil and cooling the reactor simultaneously after heating the mixture up to soap melting point.

The crystallization in SOY 2 process was induced by keeping the mixture at $180^{\circ} \mathrm{C}$ for one hour. In this condition, close to lithium 12-hydroxisterate melting point, a transition to waxy phase is induced [5].

In SOY3 and SOY4 the soap produced was kept dispersed in the system and no crystallization process was induced because of low temperature achieved. As consequence, a higher cone penetration can be observed showing a softer structure. It is important to emphasize that the same total amount of soybean oil has been added to all batches.

Lowering maximum process temperature, an acidity reduction can be observed, and a quite neutral grease was obtained. This acidity probably is caused by hydrolysis of soybean oil with water generated during saponification reaction, even with vacuum applied. In higher temperatures this chemical reaction is easier to be promoted.

Once the same amount of acid and alkali has been added and no significant alkalinity was observed at the final grease, it can be assumed that saponification reaction was complete and that soap content is similar to all batches. On the other hand it is not possible to ensure that the saponification had happened only with the acid added and not with acid generated from soybean oil eventual hydrolysis.

Even producing softer greases, the lower temperature processes resulted in higher dropping points.

The differences between 10,000 time and 60 time worked penetrations presented the following sequence from best to worst result: SOY3 > SOY2 > SOY4 > SOY1.

The roll stability test presented similar results for all greases. SOY 3 became harder after the procedure.
The results of the two traditional grease tests selected to evaluate thickener structure (cone penetration difference and roll stability) indicate SOY3 as the best performance product.

On the other hand, all rheological properties showed reduction when temperature process decreases. A storage modulus reduction leads to less resistant structures in the solid phase under low stresses. It was followed by LVE stress reduction too, meaning that the linear viscoelastic stress range is reduced with the decreasing maximum process temperature.

The storage (G') and viscous (G') modulus variation with \% strain are presented in Figure 3.

The storage modulus reduction from SOY1 to SOY4 batch can be noticed.

SOY3 presented a particular behavior which is a range of \%strain at which storage and viscous modulus presented quite the same value. Instead of a single point it seems that the yield stress becomes a stress range. The yield stress considered for results evaluations was the one at the end of this range, the highest value.

Rheological properties of SOY4 suggest that it has the least stress resistant structure probably because it did not have an appropriate crystallization. Roll stability and 10,000 time worked penetration do not point in the same direction. Even being the softest grease (60 time worked penetration) with the same amount of added oil, proving that less oil was trapped inside thickener structure, SOY4 presented the highest dropping point. So its structure seems to be more resistant to temperature raise than the one from the other greases.

Results indicate that it is possible to produce quite neutral greases with vegetable oils by reducing the maximum process temperature. Regular structure stability tests for greases indicate that these changes in process may not compromise performance in these tests but a higher soap content will be necessary to achieve the same consistency obtained from SOY1 process.

On the other hand, rheological tests showed a significant drop in structure stress resistance, showing that SOY4 flows more easily than the other samples.

The correlation between rheological properties and lubricant performance is not perfectly known yet but it has already been shown that greases with lower yield stresses, similar to the one presented by SOY4, present lower friction coefficients at high speeds [6]. So it is expected that 
Table 3. Produced greases evaluation.

\begin{tabular}{|c|c|c|c|c|}
\hline & SOY1 & SOY2 & SOY3 & SOY4 \\
\hline 60 time worked penetration- $\mathrm{A}, \mathrm{mm} / 10$ & 290 & 302 & 322 & 363 \\
\hline 10,000 time worked penetration- $\mathrm{B}, \mathrm{mm} / 10$ & 311 & 310 & 322 & 376 \\
\hline Difference (B-A), $\mathrm{mm} / 10$ & 21 & 8 & 0 & 13 \\
\hline Roll Stability (difference between cone penetrations before and after test), $\mathrm{mm} / 10$ & 3 & 3 & -5 & 7 \\
\hline Dropping point, ${ }^{\circ} \mathrm{C}$ & 162 & 169 & 184 & 190 \\
\hline Acidity $\left(\% \mathrm{H}^{+}\right)$or Alkalinity $\left(\% \mathrm{OH}^{-}\right)$ & $8.2 \mathrm{H}^{+}$ & $6.8 \mathrm{H}^{+}$ & $2.1 \mathrm{H}^{+}$ & $0.05 \mathrm{OH}^{-}$ \\
\hline LVE Stress, Pa & 416.9 & 251.4 & 65.3 & 19.4 \\
\hline Yield Stress, Pa & 1911.3 & 1078.4 & 1051.1 & 173.7 \\
\hline $\mathrm{G}, \mathrm{Pa}$ & 233,079 & 174,535 & 63,740 & 18,842 \\
\hline
\end{tabular}

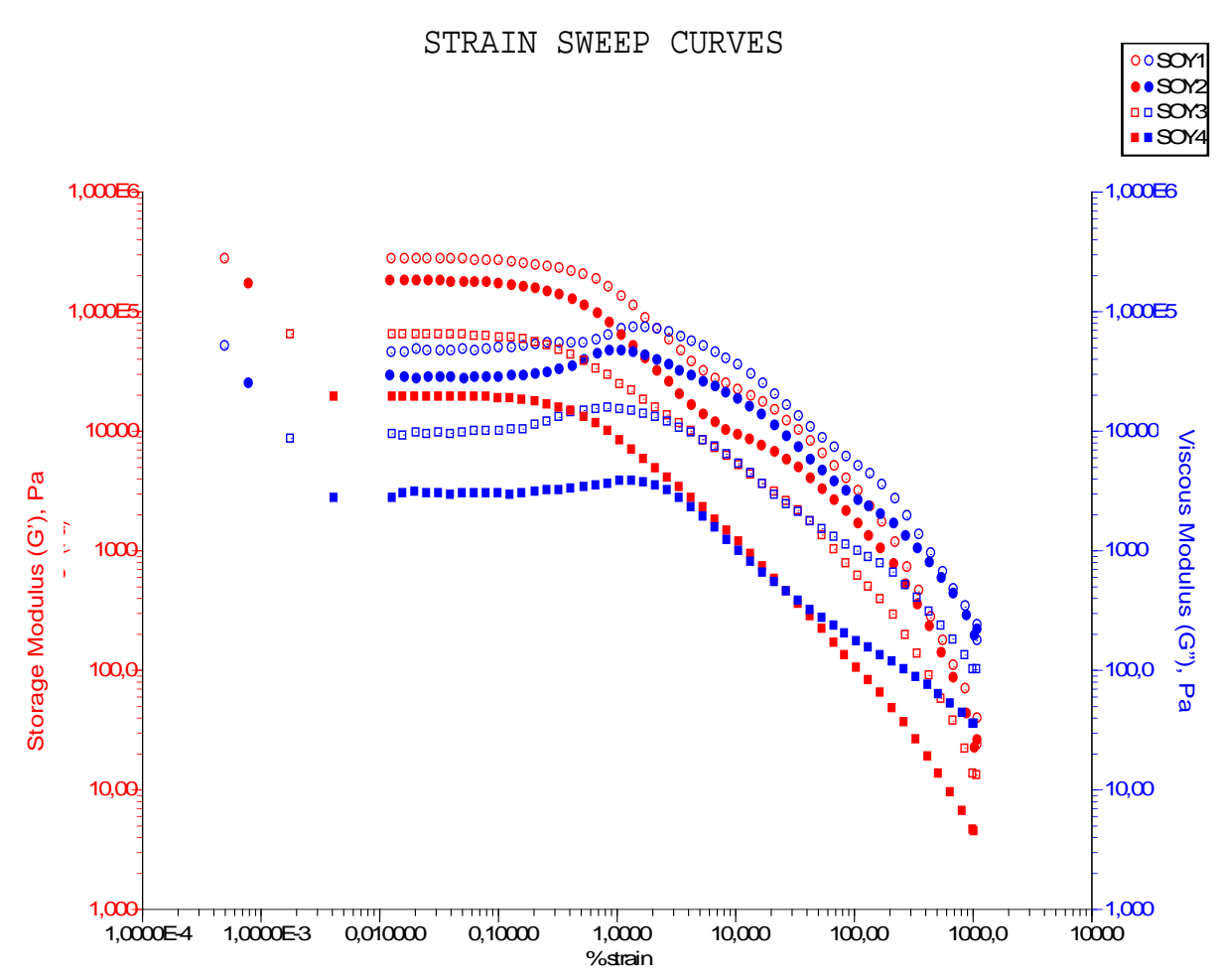

Figure 3. Strain sweep curves.

SOY4 presents a good performance at high speed applications.

\section{Conclusions}

Reducing the maximum temperature of a grease process resulted in less acid and even quite neutral greases. On the other hand, with the same amount of added oil, it resulted in a softer product.

The traditional grease structure tests, like difference between a 10,000 time and a 60 time worked penetrations and roll stability did not present significantly different performances with the process temperature changes tested. In some cases, these test results were even better. The dropping point improved with temperature lowering.
Rheological properties were measured in a dynamic shear rheometer and results dropped with the process temperature reduction, showing an improvement in flowing properties. They are not well correlated with grease lubrication yet but a better flow behavior is important for lubricant replenishment at the contact point, specially in high speed applications.

The lower temperatures tested during grease production with soybean oil preserved vegetable oil properties and produced greases with good thickener structure properties.

\section{REFERENCES}

[1] J. Korff and A. Cristiano, "Requirements of Environmentally Acceptable Greases According to 'Blue Angel Reg- 
ulation',” NLGI Spokesman, Vol. 64, No. 8, 2000, pp. 2229.

[2] M. Miller, "EPA to Require Green Lubes for Vessels," Lubes'N'Greases, Vol. 19, No. 1, 2013, pp. 22-26.

[3] O. Florea, M. Luca, A. Constantinescu and D. Florescu, "The Influence of Lubricating Fluid Type on the Properties of Biodegradable Greases," Journal of Synthetic Lubrication, Vol. 19, No. 4, 2003, pp. 303-313. http://dx.doi.org/10.1002/jsl.3000190404

[4] ASTM International, "Annual Book of ASTM Standards,”
ASTM International, West Conshohocken, 2013.

[5] M. A. Delgado, M. C. Sánchez, C. Valencia, J. M. Franco and C. Gallegos, "Relationship among Microstructure, Rheology and Processing of a Lithium Lubricating Grease,” Chemical Engineering Research and Design, Vol. 83, No. 9, 2005, pp. 1085-1092. http://dx.doi.org/10.1205/cherd.04311

[6] J. Laüger and P. Heyer, “Temperature-Dependent Rheology and Tribology of Lubricating Greases,” NLGI Spokesman, Vol. 72, No. 10, 2009, pp. 9-19. 